\title{
Case Representation and Occurrence of Lymphatic Filariasis in two Blocks of Purulia District (West Bengal, India)
}

\author{
Abhisek Mandal ${ }^{1}$, Shyamapada Mandal ${ }^{2}$, Soumendranath Chatterjee ${ }^{1^{*}}$
}

${ }^{1}$ Parasitology and Microbiology Research Laboratory, Department of Zoology, University of Burdwan, Burdwan-713104, India

${ }^{2}$ Laboratory of Microbiology and Experimental Medicine, Department of Zoology, University of Gour Banga, Malda-732103, India

*comespondence to: soumen.microbiology@gmail.com

\begin{abstract}
Lymphatic filariasis (LF), which occurs in the tropical and sub-tropical world, also prevails in various parts of West Bengal state (India), but updated information are not available in scientific literature from the studied region (Purulia district, West Bengal). This preliminary study reports the occurrence of varied form of the disease in two blocks of Purulia: Bandwan and Manbazar II. Among a total of 27 LF cases, 17 were male, who represented hydrocele $(n=11)$ and the leg swelling $(n=6)$, and 10 were females: 8 representing leg swelling and two hand swelling. No male patient had hand swelling, while among 8 female patients with leg swelling, one additionally had hand swelling. In addition, this paper represents a case of 62 year male individual suffering from $L F$ for almost last 50 years and having a combination of indigenous treatment with plant extracts, homeopathic as well as allopathic drugs. The comparatively higher rate of infection among males might be due to their susceptibility to the disease or more exposure to the mosquito bites. Further, extensive surveillance of the disease, and community awareness as well as health education are needed in order to combat the disease and related stigma from this part of the globe.
\end{abstract}

KEYWORDS: Lymphatic filariasis, case and surveillance, hand and leg swelling, Purulia.

\section{INTRODUCTION}

Lymphatic filariasis (LF), which is majorly caused with the infection of microfilariae of Wuchereria bancrofti and borne by the species of Culex mosquitoes, is a debilitating neglected tropical diseases, and the second largest cause of long term and permanent disability, because of swelling of the limbs (lymphoedema), and elephantiasis or lymphoedema of the scrotum (hydrocele) in the later stage [1-3]. The occurrence of LF in different parts of India has been well documented [4]. In West Bengal state (India), where the disease is endemic, reports are also available from adjacent districts of Purulia (a hyper endemic district) [5-8], whereas LF data availability is scanty from the studied regions. Prevalence of LF among population in two different blocks: Balarampur and Bandwan, were surveyed with hand swelling and leg swelling, which were common among males and females, while males had hydrocele presentation too [9]; thereafter, the LF endemicity in Purulia had been recorded during 2018 [1]. This preliminary study communicates a case representation and occurrence of LF among people in two blocks: Bandwan and Manbazar II, Purulia district (West Bengal state, India).

\section{METHODS}

The data and information on LF were collected from block primary health centres (Bandwan block and Manbazar II block) with official permission. The data were processed for age-wise distribution of LF occurrence among individuals, both male and female, from different villages attending the said hospitals for treatment. The mean ages of the patients (from the blocks: Bandwan and Manbazar II) were calculated, and $95 \%$ confidential intervals (CI) were determined, for both the males and females, using MS Excel 2013. The LF incidences for the patients from villages under the two blocks considered in the study were recorded either as hand swelling, leg swelling and scrotal swelling (hydrocele for male patients), or the combinations, if any. Also, a case of 62 year old male individual suffering from LF for almost last 50 years and having a combination of indigenous treatments with plant extracts, homeopathic as well as allopathic drugs.

\section{RESULTS AND DISCUSSION \\ Block level filariasis occurrence}

This study is first to communicate the incidence of LF among people of backward villages under two blocks: Bandwan and Manbazar of Purulia district (West Bengal, India). The number of cases with various forms of LF: hydrocele (Bandwan block: 5, Manbazar II block: 6), hand swelling (Bandwan block: 2; all female patients) and leg swelling (Bandwan block: 9; 6 male and 3 female, Manbazar II block: 5; all females) are represented in Figure 1A. Male cases were devoid of hand swelling, while among 8 female patients with leg swelling one represented hand swelling as well. Therefore, a total of 27 lymphatic filariasis cases were recorded with the microfilariae 
infection by blood test. The age and gender discrimination of LF cases from both Bandwan block and Manbazar II block are represented in Figure 1B. The mean age of male and female patients from Bandwan block were 41.5 year $(95 \%$ confidence interval (CI): 33.1-49.9) and 53.6 year (95\% CI: 48.9-58.3), respectively, while for Manbazar Il block were 37.3 year (95\% CI: 24.9-49.7) and 39.2 year (95\% CI: 27.0-51.4), respectively. People living in endemic regions permanently or for a long time are at the greater risk for infection, because of poverty, lack of health education and ignorance, and repeated mosquito bites $[1,10]$. For the prevention and treatment of chronic manifestations of lymphatic filariasis long term care is suggestive with good hygiene [11].

\section{Case representation}

A 62 year old male individual is suffering from LF since his boyhood once when he suddenly noticed swelling of his leg on the left (Figure 2) during playing football. He took indigenous treatment and got cured. But swelling appeared again and the same treatment procedure was followed to cure his leg, and associated fever too. Since the clinical situation was same in repeated manners he visited multiple doctors practicing homeopathy, allopathic and ayurvedic as well. He tried with homely made plant based therapy with the paste of a combination of banyan tree (Ficus benghalensis) twig, apang (Achyranthes aspera) and Begonia roots, and fresh turmeric (Curcuma longa) that cured him temporarily. His treatment with homeopathic medicine 'faylo fresh' also had similar effect; the patient experiences with both fever and swelling of left leg, and repetition of appearance and disappearance of the conditions (fever and leg swelling) as well. Nevertheless he is with faylo fresh treatment since 1970. Afebrile left leg swelling persistence is notable chronic feature of LF for the individual without further complication. Therefore, this LF case is of rare type, and unmatched one [12].

\section{CONCLUSION}

The current preliminary report authenticated the occurrence of LF among people at different remote tribal villages in jungle surrounding dry and arid regions (Bandwan and Manbazar II blocks) of Purulia district (West Bengal, India). Avoiding mosquito bites is suggestive for the local people

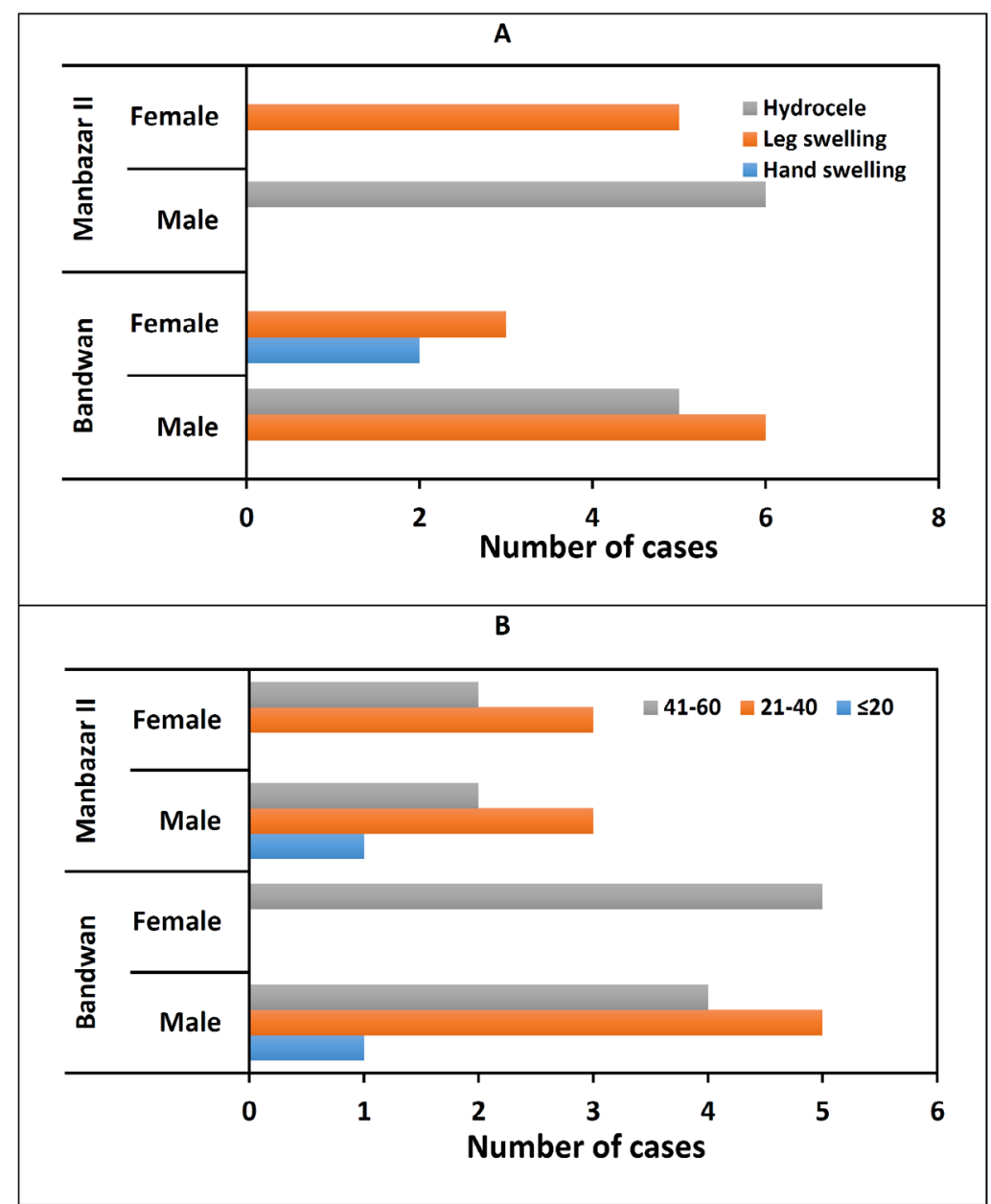

Figure 1: Lymphatic filariasis (LF) cases in Bandwan block and Manbazar II block of Purulia district (West Bengal, India): (A) genderwise category of LF cases; (B) gender-wise age distribution of $L F$ cases (digits within the figure indicate the age of cases in years). 


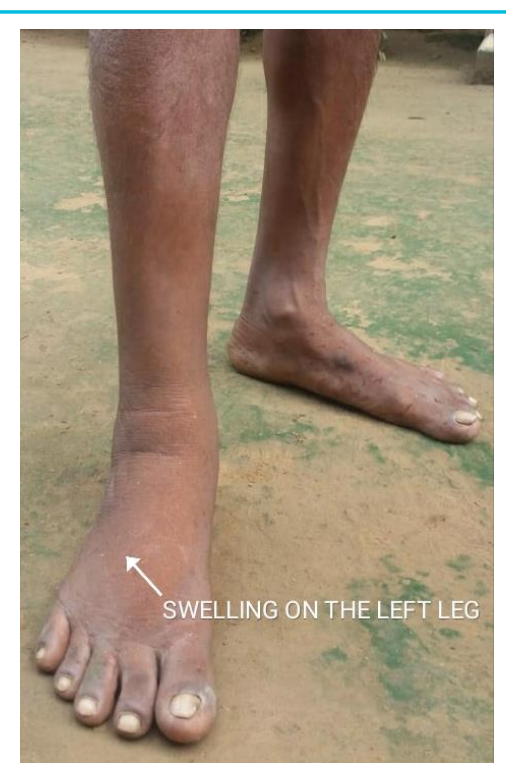

Figure 2: Lymphatic filariasis case with swelling of left leg.

in the prevention of LF contraction. Further extensive and regular surveillance of LF as well as experimental studies are needed to define the basic understanding of the disease among people of this part of the globe, for safer health with protective hygiene and required sanitation; this could limit the LF transmission.

\section{Acknowledgement}

The Block Medical Officer in Health (BMOH) of Primary Health Centres at Bandwan block and Manbazar II block are greatly acknowledged for their help in permitting filariasis data collection

\section{Conflicts of interest}

There is no conflict of interest to declare by the authors.

\section{Authors' contribution}

AM: surveyed and collected data, and wrote the paper; SM: analysed data and discussed the paper; SC: designed the study, collected and analysed data.

\section{References}

1. GLRA India, (2020): Neglected tropical diseases. Available at: https:// www.glraindia.org/our-work/NTD (Accessed on August 28, 2020).

2. Local Burden of Disease 2019 Neglected Tropical Diseases Collaborators, (2020): The global distribution of lymphatic filariasis, 2000-18: a geospatial analysis. Lancet Global Health, 8: E1186-E1194.
3. World Health Organization, (2020): Lymphatic filariasis. Available at: https://www.who.int/news-room/fact-sheets/detail/lymphatic-filariasis (Accessed on August 30, 2020).

4. Sabesan, S., Vanamail, P., Raju, K., Jambulingam, P., (2010): Lymphatic filariasis in India: epidemiology and control measures. J Postgrad Med, 56: 232-238.

5. Biswas, D.K., Bhunia, R., Biswas, P., Das, P., (2016): School Based Filaria Transmission Assessment Survey at Purba Medinipur District, West Bengal; India in 2014. International Multispecialty Journal of Health, 2: 11-19.

6. Rudra, S.K., Chandar, G., (1998): Bancroftian filariasis in tribal population of Bankura district, West Bengal, India. Jpn J Trop Med Hyg, 26: 109-112.

7. Azmi, S.A., Das, S., Chatterjee, S., (2015): Seasonal prevalence and blood meal analysis of filarial vector Culex quinquefasciatus in coastal areas of Digha, West Bengal, India. J Vector Borne Dis, 52: 252-256.

8. Chandra G, Chatterjee SN, Das S, Sarkar N. Lymphatic filariasis in the coastal areas of Digha, West Bengal, India. Tropical Doctor 2007; 37 : 136-139

9. Haldar, A., Mundle, M., Haldar, S., Biswas, A.K., Mitra, D.P., Mahaptra, B.S., (2001): Mass DEC campaign for filariasis in a hyper endemic district of West Bengal. J Commun Dis, 33: 192-197.

10. World Health Organization, (202): Lymphatic filariasis: halfway towards eliminating lymphatic filariasis: Progress report 2000-2009 and strategic plan 2010-2020 of the global programme to eliminate. Available at: http:/origin.searo.who.int/entity/vector_borne_tropical_diseases/topics/ lymphatic_filariasis/LFREP.pdf (Accessed on August 30, 2020).

11. Specht, S., Suma, T.K., Pedrique, B., Hoerauf, A., (2019): Elimination of lymphatic filariasis in South East Asia. British Med J, 364. doi: 10.1136/ bmj.k5198

12. Thaplival, N., Joshi, U., Bhadani, P., Jha, R.S., (2009): First report of filariasis in a non-endemic hill state of India. Indian J Pathol Microbiol, 52: 293-294.

Citation: Abhisek Mandal, Shyamapada Mandal, Soumendranath Chatterjee, "Case Representation and Occurrence of Lymphatic Filariasis in two Blocks of Purulia District (West Bengal, India)", American Research Journal of Biosciences vol 6, no. 1, 2020, pp. 1-3.

Copyright (C) 2020, Soumendranath Chatterjee, et al. This is an open access article distributed under the Creative Commons Attribution License, which permits unrestricted use, distribution, and reproduction in any medium, provided the original work is properly cited. 